See discussions, stats, and author profiles for this publication at: https://www.researchgate.net/publication/249929141

\title{
Introduction: Approaches to Genre
}

Article in Folia Linguistica - January 2005

DOI: 10.1515/flin.2005.39.1-2.1

\section{CITATIONS}

13

2 authors:

A Peter Muntigl

Simon Fraser University

48 PUBLICATIONS 692 CITATIONS

SEE PROFILE
READS

271

Some of the authors of this publication are also working on these related projects:

Candidates' self presentations as “ordinary people” on Twitter during the 2016 Austrian presidential election campaign View project

Ruptures in affiliation: An examination of the discursive-interactional practices used to damage and repair social cohesion between speakers. View project 


\section{Introduction: Approaches to Genre}

Peter Muntigl \& Helmut Gruber

\section{Introductory Remarks}

This volume is based on a panel that Peter Muntigl, Helmut Gruber and Eija Ventola organized for the $8^{\text {th }}$ International Pragmatics Association Conference in Toronto, July 2003. The panel was entitled "Approaches to Genre" and had aimed at bringing together scholars from different backgrounds in genre research in order to initiate a critical dialogue. Mostly due to the unfortunate circumstances surrounding this IPRA conference (the SARS crisis that troubled many prospective conference attendants in July 2003), not all panel participants actually attended the conference. All participants, excluding Carol Berkenkotter and Gudrun Held, sent in their papers, which were then read and discussed at the conference. Unfortunately, one of the panel participants (Gunter Senft) was not able to participate in this volume. Glenn Stillar, who did not present a paper at the IPRA panel but who nonetheless attended our panel, was asked to contribute an article as his work shows that genre research is not confined to the investigation of language and interaction but may also be fruitfully applied in research on other semiotic systems like music. We would especially like to thank Wolfgang U. Dressler for the invitation to publish the papers of our panel as a Special Issue of Folia Linguistica.

In section 2 of this introduction, we will provide a brief sketch of the research traditions on genre in those two academic discourse communities where the panel participants came from, namely the English and the German speaking countries. Of course, there are other research traditions in other parts of the world, but we do not aim at giving a comprehensive state-of-the-art overview here, but rather want to contextualise the papers in this volume. In section 3 of this introductory chapter we shall introduce each paper of the present volume.

\section{Genre research traditions in two academic discourse communities}

As Swales (1990) has already pointed out in his book on "Genre Analysis" the term genre has roots in various academic disciplines such as literary and folklore studies, linguistics and rhetoric. An overview of genre in terms of its broad historical development goes much beyond the scope of this special issue - for such an overview readers are asked to consult Swales (1990), Günthner \& Knoblauch (1995) and Johns (2002). Instead we will provide a brief 
overview of genre research that takes 'discourse analysis' as a point of departure. Furthermore, this overview will restrict itself to English and German discourse communities.

\subsection{The English research tradition(s)}

In North America the concept of genre received due attention from Hymes' (1972) work on communicative competence. For Hymes genre consisted of a textual category that made up an integral part of a communicative event. During this time the stage was being set for examining larger-than-clause instances of texts. This focus was also making itself felt in conversation analytic work that took account of activity types. As Levinson (1992[1979]:69) explains:

“...I take the notion of activity type to refer to a fuzzy category whose focal members are goal-defined, socially constituted, bounded, events with constraints on participants, setting, and so on, but above all on the kinds of allowable contributions. Paradigm examples would be teaching, a job interview, a jural interrogation, a football game, a task in a workshop, a dinner party, and so on."

Building upon Levinson's claims, Drew and Heritage (1992:22) have incorporated the notion of activity type within the broader category of "institutional talk", proposing that it involves an orientation to institutional goals, special and particular constraints on speakers' contributions and special inferential frameworks.

The term genre plays a much more central role in the approach known as The New Rhetoric (for an overview see Freedman and Medway 1994). In this approach emphasis is given to the discourse communities in which genres are realized. Genres are, in this sense, cultural practices that orient to social purposes (Berkenkotter and Huckin 1995; Coe 2002; Miller 1984). Furthermore, genres are not seen as stable or static text types but as evolving cultural practices. In his examination of the experimental article in science Bazerman (1988:8) strongly enforces this view when he suggests that:

"Formal definitions, expected features, institutional force, impact, and understandings of the genre vary through time, place and situation. And that variation is an important part of the story. Each new text produced within a genre reinforces or remolds some aspect of the genre; each reading of a text reshapes the social understanding. The genre does not exist apart from its history, and that history continues with each new text invoking the genre." 
Approaches within the New Rhetoric paradigm tend to be concerned with pedagogy or literacy. Flowerdew (2002) argues that this approach emphasizes the social and cultural situation over the text; that is, primacy is given to a text's social purpose rather than its linguistic realization. Increased focus on textual features is provided in an approach from Canada known as Communication Linguistics (Gregory 1985; Malcolm 1985, this volume). However, in this approach the generic structure of a text is viewed in terms of both the situation and the discourse. In Communication Linguistics genre is used interchangeably with register (see Malcolm this volume). Essentially, register refers to "the configuration of the linguistic meaning resources that the members of a culture typically associate with a given generic situation" (Gregory 1985:127). When analyzing texts and their generic structure, these linguists also make use of the terms phase and transition. Generally, phase refers to a stretch of text that reveals a certain measure of consistency in terms of its linguistic realizations (ideational, interpersonal and textual). Transition, on the other hand, refers to the movement from one phase to the next. More recently, the concept of rhetorical strategy has also been developed to account for types of literary discourse such as description, narration, interior monologue and dialogue (Malcolm this volume).

Over the past twenty years much interest in genre has come from Australia in an approach known as Systemic Functional Linguistics (hereafter SFL). Within this framework genre is viewed as a social activity. According to Martin (1985:250):

"Genre are how things get done, when language is used to accomplish them. They range from literary to far from literary forms: poems, narratives, expositions, lectures, seminars, recipes, manuals, appointment making, service encounters, news broadcasts and so on. The term genre is used here to embrace each of the linguistically realized activity types which comprise so much of our culture. Its meaning extends far beyond its use in literacy studies to refer to different kinds of verbal art, though each of these does remain a genre in the usage here."

Genre research in SFL has been largely influenced by Barthes (1977), Hjelmslev (1961), Labov and Waletzky (1967), Mitchell (1957/75) and Pike (1982) (For an overview of the historical influences of genre research within SFL see Martin 1992, 1999; Ventola 1987, this volume). As in Communication Linguistics, a genre analysis takes into account both text and context, a central premise being that different types of context are realized in different types of language patterns. In general, genres in SFL are viewed as social activities and are often associated with the following six characteristics: 1) Genres are goal oriented; 2) Genres unfold in terms of stages or phases; 3) The set of genres, taken together, realize a cultural 
potential or all possible contexts of culture; 4) Genres consist of families that contain fuzzy borders; 5) Genres often pattern together to form what are termed macro-genres; and 6) Genres may be realized by various semiotic modes such as spoken/written language, gesture, image, body position and others. ${ }^{1}$ We will briefly address each of these points below.

Genres are goal-oriented: A classic example of a goal-oriented genre is the narrative (Labov \& Waletzky 1967). The overarching 'aim' of this genre is to convey an episode of experience in which a protagonist is able to resolve some form of trouble or 'crisis'. Thus, the language used by the story-teller may be seen as orienting to the main goal of resolving the complicating action. These goals are culturally shared; they are not 'private' individual goals. Genres unfold in terms of stages or phases: Returning to the narrative, Labov \& Waletsky (1967) proposed that narratives unfold through the following stages ('^’ means 'is followed by'): Orientation ${ }^{\wedge}$ Complication $\wedge$ Evaluation ${ }^{\wedge}$ Resolution ${ }^{\wedge}$ Coda. Each stage is firmly grounded in distinct language patterns. Therefore, the transition from one stage to the next is realized by the phasing together of distinct kinds of meanings. This does not mean that there must be one type of meaning or clause associated with any given stage. Rather, the meaningful import of a stage may be realized by a number of varying combinations of language patterns.

Genre as Context of Culture: Genre is often associated with the context of culture (Martin 1999). From this view genres consist of the types of social practices that are available to members of a culture; that is, genres enable the members of a culture to make meanings in a variety of social situations. In this way, genres are viewed as a cultural potential through which a number of meaning-making practices may become realized. Since they form part of the social context, genres are distinct from language. In addition, they form a semiotic system in their own right. As a cultural potential, genres are realized in contexts of situation, which are, in turn, realized by language (detailed discussions describing genre as a semiotic system may be found in Martin 1992:493-496, 1999).

Genres are grouped into families: Martin (2002:274) proposes that genres tend to cluster within families such as story, expository, service encounter, appointment, interview and control. Each family contains a variety of types that share common features. Story genres such as recounts, exemplums, anecdotes and narratives, for example, tend to be episodic and involve a sequence of events. The borders of these genre families are, however, fuzzy. This

\footnotetext{
${ }^{1}$ Admittedly, we are painting an incorrect homogeneous view of genre theory in SFL. What we have been describing is essentially the genre theory espoused by the "Sydney School" led by Jim Martin. Halliday (1978), by contrast, saw genre as part of the rhetorical function of the contextual variable mode, and not as a separate semiotic system. Hasan (1985), in a similar vein, aligned genre with register, or the contextual variable field. For Hasan (1985:108), a genre is associated with a specific semantic potential (or register) and specific contextual configuration (configuration of the contextual variables field, tenor and mode). Genres also have obligatory and optional elements (or stages), and it is the obligatory elements that define the genre.
} 
means that there always exist certain genres that may fall between families. As an example, Martin (2002:272) mentions the historical account genre, which shares features of both the story and expository family. This genre contains a series of chained events as stories often do, and it involves causal explanation, which is more typical of exposition. Such topological descriptions of genres that include fuzzy borders do not illustrate a weakness in the theory. Instead, it points to the elasticity and dynamism of social activities.

Macro-genres: Genres, especially when occurring in conversation, rarely occur in isolation. They may be either embedded within other genres (Gruber \& Muntigl this volume; Martin 1995, Muntigl 2004a, 2004b) or they may occur sequentially before or after another genre (Christie 1998, Jordens 2002, Muntigl 2004b). A macro-genre analysis, therefore, provides a framework for examining complex forms of text variation (see also Berkenkotter this volume on "genre sets or systems").

Genre and Semiotic Modes: Although much genre research has focused on language as the principal semiotic mode that realizes a genre, other semiotic modes often do play a significant role. For instance, it has been shown that gesture (Muntigl 2005) and image (Huemer 2001, van Leeuwen 1993) work in tandem with 'language' to realize such genres as explanations and job advertisements. Therefore, in analyses of all types of texts researchers should be sensitive to the interplay between different semiotic modes that are used to phase together different kinds of meanings (see Lemke, Stillar and Ventola this volume for discussions of the importance of multi-modal analyses).

\subsection{The German research tradition}

In the German speaking countries, linguistic research on "genre" is characterized by terminological inconsistency and theoretical variety, which makes it difficult to give a short overview on theoretical developments and the current research situation. Nonetheless, we will attempt to sketch the historical developments and the major theoretical strands in German research on genre.

In Germany, the interest for research on "genres" ("Textsorten") originated in the early 70ies. At this time, Barbara Sandig presented an influential classification scheme which conceived of genres as combinations of textual features (Sandig, 1972). The volume in which this paper was published (Gülich \& Raible, 1972), and Werlich's "Typology of texts" (Werlich, 1975) mark the early days of genre research in the German speaking context. These early publications already show the terminological inconsistency which is characteristic for this research area until today. The term "genre" (which is a foreign word of French origin in 
German just as in English) is not used in German linguistics; rather, its use is restricted to literary studies where it refers to traditional literal genres like "poem", "drama", "novel" etc. Most scholars in text linguistics rather use the terms "Textsorte" (literally "text sort", usually translated as "genre" in English) or "Texttyp" ("text type") to refer to groups of texts that share certain characteristics.

However, as Adamzik (1995) in a research overview shows, the term "Textsorte" (although widely used) is not understood in the same sense by all scholars. Adamzik differentiates between three "uses" of the term in German research up to the middle of the nineties. In a "loose" sense, "Textsorte" denotes a class of texts that are selected and grouped together according to a theoretically uninformed ad-hoc classification. The only sense of these classifications is the establishing of a text corpus, which is then scrutinized under various perspectives. This kind of classification and investigation occurs mainly in applied linguistic contexts (LSP research in relation to Teaching German as a Foreign/ Second Language and Translation Studies). Although this research tradition may have its merits in the mentioned areas, it did and does not have any impact on a linguistic modelling of genres.

In a "narrow" sense (Adamzik, 1995), the term "Textsorte" is used to refer to classes of texts that are specified by certain characteristics (features) of medium, communicative functions, and kinds of topical development. For these text classifications on a rather low level of abstraction, some scholars introduced the term "Textmuster" ("pattern of text" Lerchner, 1991; Michel, 1990; Sandig, 1972). With regard to theory formation, these approaches do not provide "grand theories" of genre classification but rather local, context oriented descriptions and limited theoretical accounts for some clearly defined genres.

Adamzik (1995) describes also a third sense in which the term "Textsorte" is used in German text linguistics and which in some sense combines the "loose" and the "narrow" approach. In this third kind of investigation, researchers start out with an everyday classification of a certain genre and assume that this everyday classification bears also relevance for a theoretical description. In later stages, researches try to model these everyday classifications in theoretical terms and thus aim at providing a theoretical account of everyday communicative practices (Dimter, 1981). Most of these investigations describe "communicative routines", i.e. highly standardized forms of communication. Again, these investigations do not aim at a global classification of all possible genres, but focus on a limited set of genres on a low level of abstraction. 
The last two approaches to "Textsorten" in German text linguistics resemble theoretically and methodologically applied genre research approaches in the Anglo-American tradition (cf. e.g. Bhatia, 1999).

But this is not yet the whole story of German "genre" research. As noted in the introductory paragraph, the second notion, which was (and still is) used to refer to classes of texts, is "Texttyp" ("text type"). This notion was introduced by Isenberg (1978) in an influential article in which he argued for a theoretical distinction between the notions of "Textsorte" and "Texttyp." Implicitly he equated the former with the first approach described above ("Textsorte" in its loose sense) and denied that this notion possessed any theoretical value for a scholarly investigation of a typology of text. For this latter (linguistic) investigation he exclusively reserved the term "Texttypologie" ("typology of texts"). According to Isenberg, the establishment of a text typology had to start out with a theoretically informed account of linguistically relevant dimensions of texts and then proceed to construct a general typology of (all possible) texts on a high level of abstraction. This text typology might then be applied in empirical investigations. Although Isenberg himself did not provide a typology of this kind, his demand for a purely theoretical approach to a typology of texts remained influential for more than 15 years, as Adamzik (1995) notes. However, as she argues, Isenberg's demand for a theoretically informed text typology and the "narrow" approach to the investigation of "Textsorten" (cf. above) do not exclude each other but may be combined. In a model of this kind, "Textsorten" refer to classes of texts on a rather low level of abstraction whereas "text types" denote groups of texts on a higher level of abstraction.

A typical example of such a model is proposed by Heinemann (e.g. Heinemann, 2000). He distinguishes between four levels of text classification: the level of grammatical characteristics and the levels of semantics, situational characteristics, and characteristics of communicative function. Each genre is characterized by a certain combination of features on each level. Groups of genres then form "classes" of genres on a more abstract level which themselves constitute "text types" on an even higher level of abstraction. In its descriptive dimension, Heinemann's model is eclectic as it combines various approaches to grammar, semantics, situation types, and communicative function. It is also strictly hierarchical, as it does not provide for relations between entities (genres, classes of genres or text types) on the same hierarchical level. In both these regards (theoretical eclecticism and hierarchical relations between genres and text types) Heinemann's model is typical for many German approaches to genre classification. Only two recent approaches to genre classification propose 
to conceive of relations between genres as "networks of genres" (Adamzik, 2001; Klein, 2000). According to Adamzik (2001), networks of genres are functionally and topically related genres which occur in certain interactional domains.

There are, however, two outstanding exceptions to the above generalization on German genre research, to which we will turn in the following two sections, namely, (1) Günthner and Knoblauch's approach to communicative genres and (2) functional pragmatics.

Günthner \& Knoblauch (1994) use the German translation of the word "genre", i.e. "Gattungen" (genres in the following) to refer to communicative entities which are stabilized solutions of recurring communicative problems in a society. Their approach is influenced by Berger \& Luckmann's phenomenological approach to the sociology of knowledge (Berger \& Luckmann, 1996). According to Günthner \& Knoblauch, genres are historically and culturally specific, socially consolidated and formalized solutions for recurring problems. They have an internal (linguistic), and an external (situational) structure as well as a "situative" level of realization that flexibly connects the abstract internal and external structures to specific situations of use. In their model, although Günthner \& Knoblauch deal only with spoken discourse, their approach could, in principle, also be applied to the analysis of written language.

Functional pragmatics is the most influential theoretical approach for the investigation of spoken language in current German discourse analysis. It has been developed by Konrad Ehlich and Jochen Rehbein and their disciples since the mid- 70ies (see e.g. Ehlich \& Rehbein, 1979, 1986; Bührig, this volume, gives an overview of the theory). The core theoretical notion of functional pragmatics is that of "speech act pattern" ("sprachliches Handlungsmuster"). Speech act patterns are standardized solutions to recurring social problems which are solved by more than one actor. They are abstract, structured entities that may be realized differently in different situational contexts. They are, however, connected with certain situations and social relations between interactants. Viewed superficially, this concept of "speech act pattern" bears some resemblance with Günthner/ Knoblauch's notion of "genre." Functional pragmatics, however, is rooted in different theoretical traditions (Karl Bühlers' functional theory of language, speech act theory, and Leontjev's theory of action, cf. Leontjew (1963/ 1971)). Additionally, functional pragmatics stresses that speech act patterns have an interactive as well as a cognitive component. I.e. during their socialization interactants acquire knowledge about relevant speech act patterns and employ this knowledge in interactions. 
Although this short overview illustrates the terminological and theoretical variety in German text linguistic research on genre, there is also a number of common features (or underlying themes) which not only connects at least most German approaches but which also relates the English and German traditions in genre research. In closing we will first list these commonalities of different approaches to genre and then shortly comment on each of them.

Characteristics of genres:

1. Genres are abstractions.

2. Genres are related to other genres in the same social field ("systems of genres", Bazerman, 1994; “interdiscursivity”, Fairclough, 1992; "Genre Families", Martin 2002) and the same genre may be used in various social fields ("genre colonies", Bhatia, 1999).

3. Genres have a stabilized, yet flexible, structure; they consist of phases and are oriented towards semiotic closure.

4. Genres activate certain situational contexts and are realized in these contexts.

5. The use of genres implies certain interpersonal roles.

6. Genres orient towards a social purpose.

7. Genres have a semiotic, social, and cognitive dimension.

8. Genres are realized in different semiotic modes, their realization being either unimodal or multi-modal.

Genres are abstractions: Genres are of a different 'semiotic order' than say, grammar or semantics; that is, they are abstract forms of socio-semiotic representations that are ultimately realized in language (or other semiotic systems - see below). In addition, genres are "ideal types" in the sense of Weberian sociology. Or, following Hasan (1985:102), we should not think of the situations in which genres become realized as "one specific situation" but as "a type of situation." Any type, from this perspective, can be instantiated by a number of different instances. Therefore, there does not exist any specific instance of a text-in-context that will realize the one true genre type, for there is no one single true type. In a similar vein, we should not think of the language that is used to realize a generic situation as too restrictive. Associated with any genre type is a semantic potential. As Hasan (1985:102) argues, "the semantic potential is a potential precisely because it can be stated as a resource - as a range within which variant selections are possible."

Genres are related to other genres in the same social field and the same genre may be used in various social fields: Genres do not stand independently of each other, but are meaningfully related to other genres in the same or a different field of social action. They may form 
networks of genres within a field or discipline. For example, the field of science is constitutive of different genres such as procedure, explanation and report (Veel 1997). Genres may also have "interdiscursive" relations to other genres (Fairclough, 1992), i.e. new ("hybrid") genres may emerge which combine elements of existing genres with new elements as a result of new communicative demands in a society (cf. Gruber, 2000 for an investigation of the hybrid genre of scholarly e-mail communication). On the other hand, a genre type may be used in different social fields and then be adapted to the special demands of these fields. For example, the genre 'procedure' may be realized as a cooking recipe, instruction manual, scientific procedure or furniture assembly directions (see Martin 1999:33). Another example includes the differences and commonalities between newspaper reports, business reports, and police reports; Bhatia (1999), coined the term "genre colony" for this phenomenon.

Genres have a stabilized, yet flexible, structure; they are subdivided into phases and are oriented towards semiotic closure: Since genres orient to culturally-shaped social goals, they tend to have (a more or less) stable structure. In other words, a genre's 'schematic' structure will be influenced by the purpose it fulfills in social interaction as well as the semiotic resources through which the genre is realized (Gruber, Muntigl, Reisigl, Rheindorf, \& Wetschanow 2004). Each phase (genre stage) has its place in the overall generic structure. Generic structures may be conceived of as sequential as well as hierarchical (cf. Gruber/ Muntigl this volume). Genres vary in the degree of "fixedness" of their structures, but all genres have clearly recognizable beginnings and endings. This structure is realized in both the obligatory phases (e.g., Complication, Evaluation and Resolution for a narrative) and the optional phases (e.g., Abstract, Orientation, Coda, etc.) of a genre.

As noted above, genres are (1) realized as texts in concrete situations and during each realization of a genre, it has to be adapted to the unique demands of this situation; and (2) the mentioned social goals in a society may change or new social goals may arise. In these cases existing genres are adapted to meet the new interactive requirements or new genres are created. It should be emphasized, however, that social goals do not, in some way, 'come first', and that genres are merely a reflex of some 'goal' that has been thought out by a culture or individual. Instead, genres and social goals evolve in a mutually elaborative way.

Genres activate certain situational contexts and are realized in these contexts: Genres are constitutive of the social goals that interactants orient to jointly in certain situations. This implies that the semiotic phases constituting the genre tend to reflect the steps in which these goals are achieved by the persons involved (e.g. in the service encounter genre a customer's "service bid" necessarily precedes the "service" of the sales person). This characteristic also 
hints at the historical aspect of genres. Genres evolve over time and they are only stabilized as long as the social goals to which they are connected remain stable. However, if a community's goals change, genres will also, since they realize these goals, change. The changing nature of genres has been well documented in Bazerman's (1988) examination of the historical development of the scientific article.

Genre use implies certain interpersonal roles: Genres are often associated with ideational aspects of language use, a genre being a kind of social activity that is used to construe a certain kind of experiential reality. Such a view often gets reinforced when, for example, oppositions between 'narrative' and 'expository' genres focus too much on the kinds of reality construction associated with either of the two genre families. For instance, narratives are often associated with focusing on participants in time and space, whereas expositions tend to generalize experience by organizing phenomena into taxonomies and cause-effect relationships (see Bruner 1986 in which he distinguishes between narrative and expository modes of thought). A genre, however, also has an interpersonal dimension, which involves interactants (reader/ writer; speaker/ hearer) in various kinds of social relationships involving hierarchy, social distance and affect. For instance, someone telling a story to a friend may construct a hierarchically neutral and intimate social relationship - the story is, of course, a co-construction between story teller and hearer. On the other hand, a moral story (an exemplum) told by a parent to a child may realize an unequal hierarchy, but nonetheless intimate, social relationship, since the parent may be sanctioning the child.

Genres orient towards a social purpose: Most approaches to genre have emphasized that genres are goal-directed or purpose-driven. Furthermore, these goals or purposes are social and culturally shared. In other words, genres are used by social groups (discourse communities) to fulfill social purposes. Some genres are only geared towards fulfilling one single purpose, whereas others may fulfill several purposes at the same time. In the latter case genres may have one main purpose and several subordinate purposes (Bhatia, 1999). Since genres reflect a cultural potential, through which its members may negotiate meanings in a variety of situations, it is impossible to speak of "private" genres (i.e. genres that were developed and are used by only one single person). This culturally shared aspect of genres, of course, does not imply that genre 'users' may not pursue their individual (tactical) aims and purposes. Rather, it means that an individual's communicative aims and intentions are always interpreted against the available inventory of culturally shared forms of communicative interaction (which of course may be exploited by individual users in order to depart from the social goals that coincide with the genre in question). Single individuals' attempts to depart 
from culturally shared goals and norms may be viewed as deviance (if individuals in fact try to "invent" new genres) or as creativity (if individuals use a recognizable genre type and attempt to transform them in ways that are still 'recognizable') by discourse communities.

Genres have a semiotic, social, and cognitive dimension: Genres can be viewed from a number of different perspectives, which include, among others, semiotic, social and cognitive perspectives. Semiotically, genres are a semiotic system - a system of meaningful choices. Genres represent what cultures can mean in terms of the range of possible options through which cultural members may co-construct meaningful activities. Genres are also social in that they are collaboratively produced, and they orient to goals or purposes that are shared among the members of a culture (or discourse community); that is, individuals learn how to mean by interacting with others in different social situations. However, by placing so much stress on the 'social' aspect of genres, an unwanted implication may arise that individuals merely 'act out' the socially shared norms and goals that are realized in genres. Although individuals collaboratively produce genres and have culturally shared expectations of a genre's social purpose, individuals may deviate from these social norms and purposes (see above), and may also recognize a text (spoken or written) as belonging to a 'different' genre. In terms of the latter, such misunderstandings (or problems in achieving intersubjectivity) may arise if interactants have different assumptions concerning the genre they are currently participating in and if they act according to these differing assumptions (e.g. speaker A assumes she is the listener in a "joke-telling" genre whereas speaker B thinks she is the teller in a "troublestelling" genre).

Genres are realized in different semiotic modes, their realization being either uni-modal or multi-modal: Genres may be exclusively realized in one medium (oral or written) of language (or other semiotic systems) or their realization may be independent of a certain medium. Whether a certain kind of realization is obligatory or not, depends largely on the social and communicative purpose of the genre. Making one's confession in the context of the Roman Catholic faith, for instance, is an oral genre as it necessitates the physical co-presence of priest and believer. As long as the regulations of the Catholic Church do not change, there will be no possibility to submit one's confession in a written medium. Many genres, however, change their mode of realization when new situational variants emerge, which necessitate genre adaptations. The service encounter genre, for instance, was originally an oral genre, but as soon as business between customers and salespersons no longer took place exclusively in markets and shops, written forms of the genre emerged. As soon as the medium commonly used to realize a genre changes, other generic features may change also as different media 
allow for (or even require) different generic structures. For instance, during the last decade, with the advent of hypertext and hypermedia, a new source of genre variation and adaptation in terms of its semiotic realization became available. Genres need no longer be realized exclusively in written or spoken medium, but they may be realized by using combinations of both written and spoken language. Furthermore other semiotic modes (i.e., semiotic systems) such as pictures, graphics, music, sounds, movie clips etc may also be phased together in the meaning-making process. These new technological possibilities of semiotic genre realization open vast new opportunities for generic variation and adaptation. One can, of course, even question whether only one single semiotic mode is ever used in meaning-making processes. Face-to-face conversation, for example, involves not just the spoken medium, but also involves other semiotic systems such as gesture, eye gaze and body position (Goodwin \& Goodwin 1992; Kendon 1990, Muntigl 2005; Streeck 1993).

\section{The contributions to this volume}

In the first article for this special issue on Approaches to Genre, Ventola re-examines her previous work on the service encounter genre (Ventola 1987). In doing so, she provides a brief and succinct history of genre and register analysis in systemic functional linguistics, and points the way for future 'state-of-the-art' work that is in need of being done. Ventola argues that more work is needed to capture the dynamic unfolding of genres, the negotiation of interpersonal meanings and the range of semiotic modes that play a part in realizing the genre. Especially in genres that involve 'material' action such as service encounters, it becomes increasingly important to consider non-verbal semiotic modes. Capturing these various semiotic modes, Ventola suggests, can be easily accomplished by video-taping social interactions.

Lemke makes the convincing argument that texts are becoming increasingly multimodal. Taking the hypertext as a point of departure, Lemke suggests that genre research must be further developed with the aim of describing and explaining how multiple semiotic modes such as language and image are co-deployed to realize genres. For instance, more focus should be given to the various intertextual links between semiotic modes. These may include such meaning relations that account for the syntagmatic and thematic organization of multiple semiotic modes. Above and beyond the importance of developing a comprehensive model of multi-modal cohesion is, for Lemke, being able to account for traversals from one text to the next. Hypertext is such a paradigm case of traversals. Through hyperlinks, for example, internet users are able to make intertextual links of various kinds, some of which are 
meaningfully related to the projected internet page and others which are much less so. Lemke argues that genre theory must consider intertextual links such as traversals, for it is 'cohesive' links of this nature that may be shaping and constituting the genres of the future.

Malcolm approaches genre research from the perspective of communication linguistics. For Malcolm genre is equated with register, a specific linguistic potential that is related to a certain situational context. Other important concepts in Malcolm's framework are phase and rhetorical strategy. Phases reflect the dynamic deployment of linguistic resources that, taken together, are consistent in register. A change in phase, therefore, marks a shift in register. Rhetorical strategies, on the other hand, refer to 'macro-functions' such as description, narration, dialogue and interior monologue. From a number of compelling examples involving literary and non-literary texts, Malcolm is able to demonstrate the vast array of text types with which the tools of communication linguistics may be brought to bear.

Gruber and Muntigl combine two approaches to text analysis (Register \& Genre Theory/ R\&GT and Rhetorical Structure Theory/ RST) to analyze a corpus of Austrian students' term papers. In the theoretical part of their paper, they discuss the relation between textual cohesion (which underlies R\&GT) and coherence (which RST tries to model) as well as the relation between serial and hierarchical textual structures. In the empirical part of the paper, they show that different genres stipulate typical co-occurrence patterns of functional genre-phases and RST text spans. They conclude that both approaches they used are complementary in accounting for textual structures and that the combination of them provides a subtle analytic procedure for the explanation of text-internal and text-external functional properties.

Berkenkotter (with Haertling Thein) argues for a critical ethnographic approach to genre research. In this approach, not only are the linguistic characteristics of discourse practices investigated but also the broad contextual surroundings of these practices (the positioning of the participants' bodies, the location and use of furniture and tools in social interaction, etc.). Central to this kind of investigation is the theoretical concept of "activity system", which Berkenkotter uses to provide an integral view of subjects, objects and instruments in a situation. After delineating her theoretical background, Berkenkotter and Thein provide two case studies (one of kids' activities in a Montessori pre-school classroom and one of students in a working class high school) in which they show impressively how the different settings shape and affect students' linguistic practices and bodily orientation.

Bührig deals with the problems of interpreted multilingual communication between doctors and patients in hospital contexts. Her theoretical background is functional pragmatics, 
a functional theory of linguistic action which has been developed in the German speaking research context during the last decades and which is most influential in German discourse analysis. After sketching the theoretical framework of functional pragmatics, Bührig applies the theory to show the ambiguities of one institutional speech act pattern, the "briefing for informed consent" in which patients in a hospital are informed about possible complications or risks of a planned medical procedure. After showing that in monolingual communication settings doctors apply two different speech act patterns to perform the "briefing for informed consent", Bührig demonstrates that the use of ad hoc lay-interpreters (which is common use in German hospitals) may further complicate the trouble-free realization of this speech act pattern, as lay-interpreters have no understanding of the underlying legal and institutional relevance of this communicative activity. Bührig's contribution shows that functional pragmatics provides a valuable framework for modelling and explaining the functions of spoken genres.

Held's paper is an exercise in applied multi-modal genre research. She investigates the communicative functions of magazine front pages in a corpus of Italian and French magazines from the last decade. Starting from the assumption that front pages serve two basic functions (advertising the product and announcing the subsequent texts in the magazine) which both contribute to an overall captatio-function, she gives an overview of the most important verbal and visual clues which are used to perform these functions. These clues are mainly of a figurative or indexical character. Some of them are genre-constitutive while others are not. Her analysis shows that the communicative functions of magazine covers are achieved by visual and verbal means on various levels from page composition to micro-level linguistic features. Held's contribution demonstrates the practical relevance of genre research for neighbouring disciplines like media studies and multi-modal semiotics.

Stillar examines what might at first blush not seem highly relevant to genre theory or research: the audio loop, which is a segment of sound that is repeated, without any noticeable gap, for an unspecified length of time. But, as Stillar cogently argues, loops are meaning making resources that have texture. A loop is not merely repetition, in the sense of a repeated word. Rather, it is through the repetition of sound that a new meaning - a new text - is created. Loops certainly have relevance to multi-modal genre research. For, as Stillar rightly points out, loops have numerous linguistic properties such as unified sequencing, continuity and conjunction, modularity and mutability. In terms of the future we may ask in what way loops will influence other media and modes (in terms of its semiotic properties), and how loops will be co-deployed with other media and modes in increasingly creative ways? 


\section{References}

Adamzik, Kirsten. (1995). „Einleitung: Aspekte und Perspektiven der Textsortenlinguistik.“ In: K. Adamzik (Ed.), Textsorten - Texttypologie. Eine kommentierte Bibliographie. Münster: Nodus Publikationen, 11-41.

Adamzik, Kirsten. (2001). „Grundfragen der kontrastiven Textologie.“ In: K. Adamzik (Ed.), Kontrastive Textologie. Untersuchungen zur deutschen und französischen Sprach- und Literaturwissenschaft. Tübingen: Stauffenburg,13-49.

Barthes, Roland. (1977). Image, Music, Text. London: Fontana.

Bazerman, Charles. (1988). Shaping Written Knowledge. The Genre and Activity of the Experimental Article in Science. Madison, Wisc.: The University of Wisconsin Press

Bazerman, Charles. (1994). "Systems of genres and the enhancement of social intentions." In: A. Freedman \& P. Medway (Eds.), Genre and New Rhetoric. London: Taylor \& Frances, 79-101.

Berger, Peter, \& Luckmann, Thomas. (1996). Die gesellschaftliche Konstruktion der Wirklichkeit: eine Theorie der Wissenssoziologie. Frankfurt/ Main: Fischer Taschenbuch Verlag.

Berkenkotter, Carol \& Thomas N. Huckin (1995). Genre Knowledge in Disciplinary Communication: Cognition/Culture/Power. Hillsdale, NJ. Erlbaum.

Bhatia, Vijay K. (1999). "Integrating products, processes, purposes and pariticipants in professional writing.“ In: C. Candlin \& K. Hyland (Eds.), Writing: Texts, Processes and Practices. London \& New York: Longman, 21-40.

Bruner, Jerome. (1986). Actual Minds, Possible Worlds. Cambridge: Harvard University Press.

Christie, Frances. (1998). "Science and apprenticeship: The pedagogic discourse." In: Reading Science: Critical and Functional Perspectives on Discourses of Science, J. R. Martin and R. Veel (Eds), London \& New York: Routledge, 152-177.

Coe, Richard. (2002). "The new rhetoric of genre: Writing political briefs.“ In: A. Johns (Ed), Genre in the Classroom: Multiple Perspectives. Mawah, NJ.: Lawrence Erlbaum Associates, 197-207.

Dimter, Matthias. (1981). Textklassenkonzepte heutiger Alltagssprache. Kommunikationssituation, Textfunktion und Textinhalt als Kategorien alltagssprachlicher Textklassifikationen. Tübingen: Niemeyer.

Drew, Paul \& Heritage, John. (1992). "Analyzing talk at work: An introduction." In: P. Drew and J. Heritage (Eds), Talk at Work: Interaction in Institutional Settings. Cambridge: Cambridge University Press, 3-65.

Ehlich, Konrad, \& Rehbein, Jochen. (1979). „Sprachliche Handlungsmuster.“ In: H.-G. Soeffner (Ed.), Interpretative Verfahren in den Sozial- und Textwissenschaften. Stuttgart: Metzler, 243-274.

Ehlich, Konrad, \& Rehbein, Jochen. (1986). Muster und Institution. Tübingen: Narr.

Fairclough, Norman. (1992). Language and Social Change. Cambridge: Polity Press.

Flowerdew, John. (2002). "Genre in the classroom: A linguistic approach.“ In: A. Johns (Ed), Genre in the Classroom: Multiple Perspectives. Mawah, NJ.: Lawrence Erlbaum Associates, 91-102.

Freedman, Avia, \& Peter Medway, eds. (1994).: Genre and the New Rhetoric. London: Taylor $\&$ Francis.

Goodwin, Charles, \& Goodwin, Marjorie. (1992). "Context, activity and participation." In: P. Auer \& A. di Luzio (Eds), The contextualization of language. Amsterdam: Benjamins, 77-99. 
Gregory, Michael. (1985). "Towards communication linguistics: A framework”. In: J. Benson and W. Greaves (Eds), Systemic Perspectives on Discourse, Vol.1. Norwood, NJ: Ablex, 119-134.

Gruber, Helmut. (2000). "Theme and intertextuality in scholarly e-mail messages". Functions of Language, 7(1), 79-115.

Gruber, Helmut, Peter Muntigl, Martin Reisigl, Markus Rheindorf \& Karin Wetschanow,. (2004). Genre, Habitus und wissenschaftliches Schreiben. Wien: Institut für Sprachwissenschaft der Universität Wien.

Gülich, Elisabeth, \& Raible (Eds.). (1972). Textsorten. Frankfurt/ Main: Athenäum Fischer.

Günthner, Susanne, \& Knoblauch, Hubert. (1994). "'Forms are the Food of Faith' Gattungen als Muster kommunikativen Handelns. “Kölner Zeitschrift für Soziologie und Sozialpsychologie, 4, 693-723.

Günthner, Susanne, \& Knoblauch, Hubert. (1995). "Culturally patterned speaking practices the analysis of communicative genres". Pragmatics, 5(1), 1-32.

Halliday, M. A. K. (1978). Language as a Social Semiotic. London. Edward Arnold.

Hasan, Ruquaiya. (1985). "The identity of a text". In: M. A. K. Halliday and R. Hasan (Eds), Language, Context and Text: Aspects of Language in a Social Semiotic Perspective. Geelong, Vic: Deakin University Press, 97-116.

Heinemann, Wolfgang. (2000). „Textsorten. Zur Diskussion um Basisklassen des Kommunizierens.“ In: K. Adamzik (Ed.), Textsorten. Reflexionen und Analysen, Tübingen: Stauffenburg Verlag, 9-31.

Hjelmself, L. (1961). Prolegomena to a Theory of Language. Madison, Wisconsin: University of Wisconsin Press.

Huemer, Birgit (2001). Aufbau und Funktion von Stellenanzeigen: Eine funktional semiotische Analyse. Unpublished M. A. Thesis. University of Vienna.

Hymes, Dell. (1972). "Modes of the interaction of language and social life." In: J. Gumperz \& D. Hymes (eds.), Directions in Sociolinguistics: The Ethnography of Communication. Philadelphia: University of Pennsylvania Press, 35-71.

Isenberg, Horst. (1978). "Probleme der Texttypologie". Variation und Determination von Texttypen. Wissenschaftliche Zeitschrift der Karl-Marx-Universität Leipzig. Gesellschafts- und sprachwissenschaftliche Reihe, 27, 565-579.

Johns, Ann (2002). „Introduction: Genre in the Classroom.“ In: A. Johns (ed.), Genre in the classroom: Multiple Perspectives. Mawah, NJ.: Lawrence Erlbaum Associates, 3-13

Jordens, Christopher. (2002). Reading Spoken Stories for Values: A Discursive Study of Cancer Survivors and their Professional Carers. Unpublished Doctoral Dissertation, University of Sydney, Australia.

Kendon, A. (1990). Conducting interaction: Patterns of behavior in focused encounters. Cambridge: Cambridge University Press.

Klein, Josef. (2000). „Intertextualität, Geltungsmodus, Texthandlungsmuster.“ In: K. Adamzik (Ed.), Textsorten. Reflexionen und Analysen. Tübingen: Stauffenburg Verlag, 31-45.

Labov, William and Waletzky, Joshua. (1967). "Narrative analysis: Oral versions of personal experience". In: J. Helm (Ed), Essays on the Verbal and Visual Arts. Seattle, WA: University of Washington Press, 12-44.

Leontjew, A. N. (1963 (german edition: 1971)). Probleme der Entwicklung des Psychischen. Berlin: Volk und Wissen.

Lerchner, Gotthard. (1991). „Musterrealisierung und Mustersignifizierung in der sprachlichen Organisation des Diskurses.“ Beiträge zur Erforschung der deutschen Sprache, 10, 3050 . 
Levinson, Stephen. (1992). “Activity types and language.“ In: P. Drew and J. Heritage (Eds), Talk at Work: Interaction in Institutional Settings, Cambridge: Cambridge University Press. 66-100. (original publication 1979: Pragmatics Microfiche vol. 3).

Malcolm, Karen. (1985). "Communication linguistics: A sample analysis". In: J. Benson and W. Greaves (Eds), Systemic Perspectives on Discourse, Vol.2. Norwood, NJ: Ablex, 136-151.

Martin, James R. (1985). "Process and text: Two aspects of semiosis.“ In: J.D. Benson and W.S. Greaves (Eds), Systemic perspectives on discourse (Vol.1). Norwood, N.J.: Ablex, 248-274.

Martin, James R. (1992). English Text. Amsterdam: John Benjamins.

Martin James R. (1995). “Text and clause: Fractal resonance”. Text 15(1), 5-42.

Martin, James R. (1999). "Modelling context: A crooked path of progress in contextual linguistics.“ In: M. Ghadessy (Ed), Text and Context in Functional Linguistics. Amsterdam: Benjamins, 25-61.

Martin, James R. (2002). “A universe of meaning - How many practices?.“ In: A. Johns (Ed), Genre in the Classroom: Multiple Perspectives. Mawah, NJ.: Lawrence Erlbaum Associates, 269-278.

Michel, Georg. (1990). „Textmuster und Stilmuster.“ In: Bahner, Schildt \& Viehweger (Eds.), Proceedings of the Fourtheenth International Congress of Linguistics, Berlin/GDR, August 10 - August 15, 1987. Berlin: Akademie. 2178 - 2180.

Miller, Carolyn R. (1984). "Genre as Social Action.” Quarterly Journal of Speech 70, 151-67. Mitchell, T. F. 1957/1975. "The Language of buying and Selling in Cyrenaica: A Situational Statement.” In: T. F. Mitchell 1975. The Principles of Firthian Linguistics. London: Longman, 167-200.

Muntigl, Peter. (2004a). "Ontogenesis in narrative therapy: A linguistic-semiotic examination of client change". Family Process 43(1), 105-124.

Muntigl, Peter. (2004b). Narrative Counselling: Social and Linguistic Processes of Change. Amsterdam: John Benjamins.

Muntigl, Peter. (2005). "Modelling multiple semiotic systems: The case of gesture and speech.“ In: E. Ventola, C. Charles \& M. Kaltenbacher (eds.), Perspectives on Multimodality, Amsterdam: John Benjamins, 31-50.

Pike, Kenneth. (1982). Linguistic Concepts: An introduction to tagmemics. Lincoln: University of Nebraska Press.

Sandig, Barbara. (1972). "Zur Differenzierung gebrauchssprachlicher Textsorten im Deutschen.“ In: E. Gülich \& W. Raible (Eds.), Textsorten. Frankfurt/ Main: Athenäum Fischer, 113-124.

Streeck, Jürgen. (1993). "Gesture as communication I: Its coordination with gaze and speech.“ Communication Monographs, 60(4), 275-99.

Swales, John. (1990). Genre Analysis. Cambridge: Cambridge University Press.

van Leeuwen, Theo. (1993). "Genre and field in critical discourse analysis". Discourse and Society, 4(2), 193-223.

Veel, Robert (1997). "Learning how to mean - scientifically speaking: Apprenticeship into scientific discourse in the secondary school". In: F. Christie and J. R. Martin (eds.), Genres and Institutions. London: Cassell, 161-195.

Ventola, Eija (1987). The Structure of Social Interaction: A Systemic Approach to the Semiotics of Service Encounters. London: Pinter.

Werlich, Egon. (1975). Typologie der Texte. Entwurf eines textlinguistischen Modells zur Grundlegung der Textpragmatik. Heidelberg: Quelle \& Meyer. 